\title{
Improved Estimators for Estimating Average Yield Using Auxiliary Variable
}

\author{
S. K. Yadav \\ Department of Statistics \\ Babasaheb Bhimrao Ambedkar University, Lucknow-226025, U.P., India \\ M. K. Dixit \\ Department of Statistics \\ Babasaheb Bhimrao Ambedkar University, Lucknow-226025, U.P., India \\ H. N. Dungana \\ School of Mathematical Sciences \\ University of Technology Sydney, Ultimo NSW 2007, Australia

\section{S. S. Mishra} \\ Department of Mathematics and Statistics (Centre of Excellence) \\ Dr. Rammanohar Lohia Avadh University, Ayodhya-224001, U.P., India \\ Corresponding author: sant_x2003@yahoo.co.in
}

(Received January 20, 2019; Accepted May 21, 2019)

\begin{abstract}
In this paper, we consider the improved estimation of average production of peppermint at block level of Barabanki district of Uttar Pradesh State (India). We suggest certain estimators for population-mean. Here, population refers to production population as study variable and auxiliary-variable refers to Area of field. We study the sampling properties naming bias and MSE of estimators, which are presently proposed by us in the paper. We compare our proposed estimators with other ones existing in literature. For the support of the theoretical findings, we carry out a numerical study for the natural population on primary data collected from Banikodar Block of Barabanki District situated in Uttar Pradesh State.
\end{abstract}

Keywords- Population variable, Auxiliary variable, Ratio-estimator, MSE, PRE.

\section{Introduction}

Literature-review reveals that applying auxiliary-information enhances estimator's efficiency under consideration whenever we estimate any parameter. It has been now evident that auxiliaryvariable technique improves the estimation process for target-population. Primary and the secondary variables have a high correlation to each other. They may have both negative and positive correlations. Ratio type estimators are preferred when primary and secondary variables are highly positively correlated while product types estimators when they have high negative correlation. As production (primary) and the area (secondary) are highly positively correlated so we consider the ratio types estimators only in the present study.

Watson (1937) used subsidiary variable and suggested the traditional regression-estimator of population mean of main variable. Usual Ratio estimator utilizing positively correlated auxiliaryinformation was given in Cochran (1940). The well-known product estimators was independently introduced by Robson (1957) and Murthy (1964) using negatively correlated auxiliary variable. 
International Journal of Mathematical, Engineering and Management Sciences

Vol. 4, No. 5, 1228-1238, 2019

https://dx.doi.org/10.33889/IJMEMS.2019.4.5-097

After Cochran (1940), various modified ratio-type-estimators are already played an important role in improving the estimation process for mean of population on the basis of auxiliary-variable having positively correlated. Some of the latest references include Yadav and Kadilar (2013), Subramani and Kumarapandiyan (2012a, 2012b), Yadav and Mishra (2015), Yadav et al. (2016), Subramani (2016), Abid et al. (2016), Cekim and Cingi (2017), Gupta and Yadav (2017, 2018), Subramani and Ajith (2017), Cekim and Kadilar (2018), Srija and Subramani (2018), Yadav et al. (2018).

The whole paper has been presented in various sections including introduction given above and the rest sections are review of existing estimators of population mean, proposed estimators, theoretical comparison of the efficiencies of various estimators with the proposed estimators, numerical study, acknowledgement of the funding agency CST UP for financial assistance for the work and finally paper ends with the references.

\section{Review of Existing Estimators}

The sample mean that does not use auxiliary information and various modified ratio-estimators of population mean applying auxiliary information are presented in the following Table 1 . The variance of sample mean and the Mean Squared Error of various estimators are also given in the following Table 1 .

Table1. Various estimators of population mean along with their mean squared errors

\begin{tabular}{|c|c|c|}
\hline S.N. & Estimator & Variance/Mean Squared Error \\
\hline 1. & $\begin{array}{l}t_{o}=\bar{y}=\frac{1}{n} \sum_{i=1}^{n} y_{i} \\
\text { Sample mean }\end{array}$ & $\lambda S_{y}^{2}=\lambda \bar{Y}^{2} C_{y}^{2}$ \\
\hline 2. & $\begin{array}{l}t_{1}=\bar{y}+\beta(\bar{X}-\bar{x}) \\
\text { Watson }(1937)\end{array}$ & $\lambda \bar{Y}^{2} C_{y}^{2}\left(1-\rho_{y x}^{2}\right)$ \\
\hline 3. & $\begin{array}{l}t_{2}=\bar{y} \frac{\bar{X}}{\bar{x}} \\
\text { Cochran }(1940)\end{array}$ & $\lambda \bar{Y}^{2}\left[C_{y}^{2}+C_{x}^{2}-2 C_{y x}\right]$ \\
\hline 4. & $\begin{array}{l}t_{3}=\bar{y} \exp \left[\frac{\bar{X}-\bar{x}}{\bar{X}+\bar{x}}\right] \\
\text { Bahl and Tuteja }(1991)\end{array}$ & $\lambda \bar{Y}^{2}\left[C_{y}^{2}+\frac{C_{x}^{2}}{4}-C_{y x}\right]$ \\
\hline 5. & $\begin{array}{l}t_{4}=\bar{y}\left(\frac{\bar{x}}{\bar{X}}\right)^{2} \\
\text { Kadilar and Cingi (2003) }\end{array}$ & $\lambda \bar{Y}^{2}\left[C_{y}^{2}+4 C_{x}^{2}-4 C_{y x}\right]$ \\
\hline 6. & $\begin{array}{l}t_{5}=\bar{y}\left(\frac{\bar{x}}{\bar{X}}\right)^{\alpha} \\
\text { Srivastava }(1967)\end{array}$ & $\begin{array}{l}\lambda \bar{Y}^{2}\left[C_{y}^{2}+\alpha^{2} C_{x}^{2}+2 \alpha C_{y x}\right] \\
\lambda \bar{Y}^{2} C_{y}^{2}\left(1-\rho_{y x}^{2}\right) \text { minimum for } \alpha_{o p t}=-C_{y x} / C_{x}^{2}\end{array}$ \\
\hline 7. & $\begin{array}{l}t_{6}=\bar{y}\left[\frac{\bar{X}}{\bar{X}+\alpha(\bar{x}-\bar{X})}\right] \\
\text { Reddy (1974) }\end{array}$ & $\begin{array}{l}\lambda \bar{Y}^{2}\left[C_{y}^{2}+\alpha^{2} C_{x}^{2}-2 \alpha C_{y x}\right] \\
\lambda \bar{Y}^{2} C_{y}^{2}\left(1-\rho_{y x}^{2}\right) \text { minimum for } \alpha_{o p t}=C_{y x} / C_{x}^{2}\end{array}$ \\
\hline
\end{tabular}


International Journal of Mathematical, Engineering and Management Sciences

Vol. 4, No. 5, 1228-1238, 2019

https://dx.doi.org/10.33889/IJMEMS.2019.4.5-097

Table 1 continued ...

\begin{tabular}{|c|c|c|}
\hline 8. & $\begin{array}{l}t_{7}=\bar{y}\left(\frac{\bar{x}}{\bar{X}}\right)^{\delta} \exp \left(\frac{\bar{X}-\bar{x}}{\bar{X}+\bar{x}}\right) \\
\operatorname{Kadilar}(2016)\end{array}$ & $\begin{array}{l}\lambda \bar{Y}^{2}\left[C_{y}^{2}+\left(\delta^{2}+\delta+\frac{1}{4}\right) C_{x}^{2}+(2 \delta+1) C_{y x}\right] \\
\lambda \bar{Y}^{2} C_{y}^{2}\left(1-\rho_{y x}^{2}\right) \text { minimum for } \delta_{o p t}=\left(\frac{1}{2}-\rho_{y x} C_{y} / C_{x}\right)\end{array}$ \\
\hline 9. & $\begin{array}{l}t_{8}=\bar{y}\left\{2-\left(\frac{\bar{x}}{\bar{X}}\right)^{\alpha} \exp \left(\frac{\xi(\bar{X}-\bar{x})}{(\bar{X}+\bar{x})}\right)\right\} \\
\text { Solanki et al. (2012) }\end{array}$ & $\begin{array}{l}\lambda \bar{Y}^{2} C_{y}^{2}\left(1-\rho_{y x}^{2}\right), \\
\text { minimum for }(2 \alpha+\xi)=2 \kappa\end{array}$ \\
\hline 10 . & $\begin{array}{l}t_{9}=\bar{y}\left(\frac{\bar{X}+Q_{1}}{\bar{x}+Q_{1}}\right) \\
\text { Al-Omari et al. (2009) }\end{array}$ & $\lambda \bar{Y}^{2}\left[C_{y}^{2}+\theta_{9}^{2} C_{x}^{2}-2 \theta_{9} C_{y x}\right], \theta_{9}=\frac{\bar{X}}{\bar{X}+Q_{1}}$ \\
\hline 11. & $\begin{array}{l}t_{10}=\bar{y}\left(\frac{\bar{X}+Q_{3}}{\bar{x}+Q_{3}}\right) \\
\text { Al-Omari et al. (2009) }\end{array}$ & $\lambda \bar{Y}^{2}\left[C_{y}^{2}+\theta_{10}^{2} C_{x}^{2}-2 \theta_{10} C_{y x}\right], \theta_{10}=\frac{\bar{X}}{\bar{X}+Q_{3}}$ \\
\hline 12. & $\begin{array}{l}t_{11}=\bar{y}\left[\frac{\bar{X}+C_{x}}{\bar{x}+C_{x}}\right] \\
\text { Sisodia and Dwivedi (1981) }\end{array}$ & $\lambda \bar{Y}^{2}\left[C_{y}^{2}+\theta_{11}^{2} C_{x}^{2}-2 \theta_{11} C_{y x}\right], \theta_{11}=\frac{\bar{X}}{\bar{X}+C_{x}}$ \\
\hline 13. & $\begin{array}{l}t_{12}=\bar{y}\left[\frac{\bar{X}+\beta_{2}}{\bar{x}+\beta_{2}}\right] \\
\text { Singh et.al (2004) }\end{array}$ & $\lambda \bar{Y}^{2}\left[C_{y}^{2}+\theta_{12}^{2} C_{x}^{2}-2 \theta_{12} C_{y x}\right], \theta_{12}=\frac{\bar{X}}{\bar{X}+\beta_{2}}$ \\
\hline 14. & $\begin{array}{l}t_{13}=\bar{y}\left[\frac{\bar{X}+\beta_{1}}{\bar{x}+\beta_{1}}\right] \\
\text { Yan and Tian (2010) }\end{array}$ & $\lambda \bar{Y}^{2}\left[C_{y}^{2}+\theta_{13}^{2} C_{x}^{2}-2 \theta_{13} C_{y x}\right], \theta_{13}=\frac{\bar{X}}{\bar{X}+\beta_{1}}$ \\
\hline 15. & $\begin{array}{l}t_{14}=\bar{y}\left[\frac{\bar{X}+\rho}{\bar{x}+\rho}\right] \\
\text { Singh and Tailor (2003) }\end{array}$ & $\lambda \bar{Y}^{2}\left[C_{y}^{2}+\theta_{14}^{2} C_{x}^{2}-2 \theta_{14} C_{y x}\right], \theta_{14}=\frac{\bar{X}}{\bar{X}+\rho}$ \\
\hline 16. & $\begin{array}{l}t_{15}=\bar{y}\left[\frac{\bar{X} C_{x}+\beta_{2}}{\bar{x} C_{x}+\beta_{2}}\right] \\
\text { Upadhyaya and Singh (1999) }\end{array}$ & $\lambda \bar{Y}^{2}\left[C_{y}^{2}+\theta_{15}^{2} C_{x}^{2}-2 \theta_{15} C_{y x}\right], \theta_{15}=\frac{\bar{X} C_{x}}{\bar{X} C_{x}+\beta_{2}}$ \\
\hline 17. & $\begin{array}{l}t_{16}=\bar{y}\left[\frac{\bar{X} \beta_{2}+C_{x}}{\bar{x} \beta_{2}+C_{x}}\right] \\
\text { Upadhyaya and Singh (1999) }\end{array}$ & $\lambda \bar{Y}^{2}\left[C_{y}^{2}+\theta_{16}^{2} C_{x}^{2}-2 \theta_{16} C_{y x}\right], \theta_{16}=\frac{\bar{X} \beta_{2}}{\bar{X} \beta_{2}+C_{x}}$ \\
\hline 18. & $\begin{array}{l}t_{17}=\bar{y}\left[\frac{\bar{X} \beta_{1}+\beta_{2}}{\bar{x} \beta_{1}+\beta_{2}}\right] \\
\text { Yan and Tian (2010) }\end{array}$ & $\lambda \bar{Y}^{2}\left[C_{y}^{2}+\theta_{17}^{2} C_{x}^{2}-2 \theta_{17} C_{y x}\right], \theta_{17}=\frac{\bar{X} \beta_{1}}{\bar{X} \beta_{1}+\beta_{2}}$ \\
\hline 19. & $\begin{array}{l}t_{18}=\bar{y}\left[\frac{\bar{X} C_{x}+\beta_{1}}{\bar{x} C_{x}+\beta_{1}}\right] \\
\text { Yan and Tian (2010) }\end{array}$ & $\lambda \bar{Y}^{2}\left[C_{y}^{2}+\theta_{18}^{2} C_{x}^{2}-2 \theta_{18} C_{y x}\right], \theta_{18}=\frac{\bar{X} C_{x}}{\bar{X} C_{x}+\beta_{1}}$ \\
\hline
\end{tabular}


International Journal of Mathematical, Engineering and Management Sciences

Vol. 4, No. 5, 1228-1238, 2019

https://dx.doi.org/10.33889/IJMEMS.2019.4.5-097

Table 1 continued ...

\begin{tabular}{|c|c|c|}
\hline 20. & $\begin{array}{l}t_{19}=\bar{y}\left[\frac{\bar{X}+M_{d}}{\bar{x}+M_{d}}\right] \\
\text { Subramani and Kumarpandiyan (2012a) }\end{array}$ & $\lambda \bar{Y}^{2}\left[C_{y}^{2}+\theta_{19}^{2} C_{x}^{2}-2 \theta_{19} C_{y x}\right], \theta_{19}=\frac{\bar{X}}{\bar{X}+M_{d}}$ \\
\hline 21. & $\begin{array}{l}t_{20}=\bar{y}\left(\frac{\bar{X} C_{x}+M_{d}}{\bar{x} C_{x}+M_{d}}\right) \\
\text { Subramani and Kumarpandiyan (2012a) }\end{array}$ & $\lambda \bar{Y}^{2}\left[C_{y}^{2}+\theta_{20}^{2} C_{x}^{2}-2 \theta_{20} C_{y x}\right], \theta_{20}=\frac{\bar{X} C_{x}}{\bar{X} C_{x}+M_{d}}$ \\
\hline 22. & $\begin{array}{l}t_{21}=\bar{y}\left(\frac{\bar{X} \beta_{1}+Q D}{\bar{x} \beta_{1}+Q D}\right) \\
\text { Jeelani et al. (2013) }\end{array}$ & $\lambda \bar{Y}^{2}\left[C_{y}^{2}+\theta_{21}^{2} C_{x}^{2}-2 \theta_{21} C_{y x}\right], \theta_{21}=\frac{\bar{X} \beta_{1}}{\bar{X} \beta_{1}+Q D}$ \\
\hline 23. & $\begin{array}{l}t_{22}=\bar{y}\left(\frac{\bar{X}+n}{\bar{x}+n}\right) \\
\text { Jerajuddin and Kishun (2016) }\end{array}$ & $\lambda \bar{Y}^{2}\left[C_{y}^{2}+\theta_{22}^{2} C_{x}^{2}-2 \theta_{22} C_{y x}\right], \theta_{22}=\frac{\bar{X}}{\bar{X}+n}$ \\
\hline 24. & $\begin{array}{l}t_{23}=\bar{y}\left(\frac{\bar{X}+Q_{r}}{\bar{x}+Q_{r}}\right) \\
\text { Subramani and Kumarpandiyan (2012b) }\end{array}$ & $\lambda \bar{Y}^{2}\left[C_{y}^{2}+\theta_{23}^{2} C_{x}^{2}-2 \theta_{23} C_{y x}\right], \theta_{23}=\frac{\bar{X}}{\bar{X}+Q_{r}}$ \\
\hline 25 . & $\begin{array}{l}t_{24}=\bar{y}\left(\frac{\bar{X}+Q_{d}}{\bar{x}+Q_{d}}\right) \\
\text { Subramani and Kumarpandiyan (2012b) }\end{array}$ & $\lambda\left[C_{y}^{2}+\theta_{24}^{2} C_{x}^{2}-2 \theta_{24} C_{y x}\right], \theta_{24}=\frac{\bar{X}}{\bar{X}+Q_{d}}$ \\
\hline 26. & $\begin{array}{l}t_{25}=\bar{y}\left(\frac{\bar{X}+Q_{a}}{\bar{x}+Q_{a}}\right) \\
\text { Subramani and Kumarpandiyan (2012b) }\end{array}$ & $\lambda\left[C_{y}^{2}+\theta_{25}^{2} C_{x}^{2}-2 \theta_{25} C_{y x}\right], \theta_{25}=\frac{\bar{X}}{\bar{X}+Q_{a}}$ \\
\hline 27. & 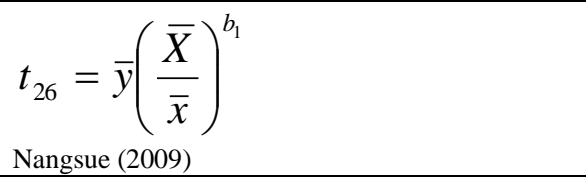 & $\lambda \bar{Y}^{2} C_{y}^{2}\left(1-\rho_{y x}^{2}\right)$ \\
\hline 28. & $\begin{array}{l}t_{27}=\bar{y}\left(\frac{\bar{X}+\rho}{\bar{x}+\rho}\right)^{b_{1}} t_{28}=\bar{y}\left(\frac{\bar{X}+C_{x}}{\bar{x}+C_{x}}\right)^{b_{1}} \\
\text { Soponviwatkul and Lawson (2017) }\end{array}$ & $\lambda \bar{Y}^{2} C_{y}^{2}\left(1-\rho_{y x}^{2}\right)$ \\
\hline 29. & $\begin{array}{l}t_{29}=\left[\omega_{1} \bar{y}+\left(1-\omega_{1}\right)\left(\bar{y} \frac{\bar{X}}{\bar{x}}\right)\right] \\
t_{30}=\left[\omega_{1} \bar{y}+\left(1-\omega_{1}\right)\left(\bar{y} \exp \frac{\bar{X}-\bar{x}}{\bar{x}-\bar{X}}\right)\right]\end{array}$ & $\begin{array}{l}\lambda \bar{Y}^{2} C_{y}^{2}\left(1-\rho_{y x}^{2}\right) \text { for } \\
\omega_{1(o p t)}=\left(1-\rho_{y x} C_{y} / C_{x}\right) \text { and } \\
\lambda \bar{Y}^{2} C_{y}^{2}\left(1-\rho_{y x}^{2}\right) \text { for } \omega_{1(o p t)}=\left(-2 \rho_{y x} C_{y} / C_{x}\right)\end{array}$ \\
\hline
\end{tabular}

\section{Proposed Class of Estimators}

Motivated by various authors in the literature, we propose the following class of estimators of population-mean using auxiliary information as, 
International Journal of Mathematical, Engineering and Management Sciences

Vol. 4, No. 5, 1228-1238, 2019

https://dx.doi.org/10.33889/IJMEMS.2019.4.5-097

$t_{p}=\bar{y}\left(\frac{a \cdot b \bar{X}+c . d}{a \cdot b \bar{x}+c . d}\right)$

where, $a, b, c$ and $d$ are either constants or the parameters of auxiliary variable under consideration.

Following Table 2 represents various members of the proposed class of estimators for different values of $a, b, c$ and $d$ putting as either constant or $M_{x}, \beta_{1}, \beta_{2}, C_{x}, \rho, n$.

Table 2. Various members of the proposed family

$$
\begin{aligned}
& t_{p 1}=\bar{y}\left(\frac{\beta_{2} M_{x} \bar{X}+\rho}{\beta_{2} M_{x} \bar{x}+\rho}\right), \quad t_{p 2}=\bar{y}\left(\frac{\beta_{2} M_{x} \bar{X}+\rho C_{x}}{\beta_{2} M_{x} \bar{x}+\rho C_{x}}\right), \quad t_{p 3}=\bar{y}\left(\frac{\beta_{1} M_{x} \bar{X}+\rho}{\beta_{1} M_{x} \bar{x}+\rho}\right), \quad t_{p 4}=\bar{y}\left(\frac{\beta_{1} M_{x} \bar{X}+\rho C_{x}}{\beta_{1} M_{x} \bar{x}+\rho C_{x}}\right), \\
& t_{p 5}=\bar{y}\left(\frac{n \bar{X}+\rho}{n \bar{x}+\rho}\right), t_{p 6}=\bar{y}\left(\frac{n \bar{X}+C_{x}}{n \bar{x}+C_{x}}\right), t_{p 7}=\bar{y}\left(\frac{n \bar{X}+\rho C_{x}}{n \bar{x}+\rho C_{x}}\right), t_{p 8}=\bar{y}\left(\frac{n \rho \bar{X}+C_{x}}{n \rho \bar{x}+C_{x}}\right), t_{p 9}=\bar{y}\left(\frac{n C_{x} \bar{X}+\rho}{n C_{x} \bar{x}+\rho}\right),
\end{aligned}
$$

Note: Many more members of the proposed family can be obtained by putting different values of the constants $a, b, c$ and $d$ of the suggested class.

\subsection{Bias and MSE of the Suggested Class}

The expressions for the bias and MSE of the suggested class are obtained using the following approximation, given as,

$\bar{y}=\bar{Y}\left(1+e_{0}\right)$ and $\bar{x}=\bar{X}\left(1+e_{1}\right)$ such that $E\left(e_{0}\right)=E\left(e_{1}\right)=0, \quad$ and $E\left(e_{0}^{2}\right)=\lambda C_{y}^{2}$,

$E\left(e_{1}^{2}\right)=\lambda C_{x}^{2}, E\left(e_{0} e_{1}\right)=\lambda C_{y x}$, where $\lambda=\frac{1-f}{n}$ and $f=\frac{n}{N}$.

Expressing $t_{p}$ in terms of $e^{\prime} s(i=0,1)$, we have $t_{p}=\bar{Y}\left(1+e_{0}\right)\left(1-\theta e_{1}\right)^{-1}$, where, $\theta=\frac{a \cdot b \bar{X}}{a \cdot b \bar{X}+c \cdot d}$.

Now expanding the right hand side of the above equation, simplifying and retaining the terms up to the approximation of order one, we have

$t_{p}=\bar{Y}\left(1+e_{0}-\theta e_{1}-\theta e_{0} e_{1}+\theta^{2} e_{1}^{2}\right)$.

Subtracting $\bar{Y}$ on both sides of the above equation, we get

$$
t_{p}-\bar{Y}=\bar{Y}\left(e_{0}-\theta e_{1}-\theta e_{0} e_{1}+\theta^{2} e_{1}^{2}\right)
$$

Taking expectations on both sides of (2) and putting values of various expectations, we get the bias of the proposed class of estimators as, 
International Journal of Mathematical, Engineering and Management Sciences

Vol. 4, No. 5, 1228-1238, 2019

https://dx.doi.org/10.33889/IJMEMS.2019.4.5-097

$$
B\left(t_{p}\right)=\lambda \bar{Y}\left(\theta^{2} C_{x}^{2}-\theta C_{y x}\right)
$$

Squaring on both sides of (2), retaining the terms up to the approximation of order one and putting values of various expectations, we get the mean squared error of the proposed class of estimators as,

$$
\begin{aligned}
& E\left(t_{p}-\bar{Y}\right)^{2} \approx \bar{Y}^{2} E\left(e_{0}^{2}+\theta^{2} e_{1}^{2}-2 \theta e_{0} e_{1}\right) \\
& \operatorname{MSE}\left(t_{p}\right)=\lambda \bar{Y}^{2}\left(C_{y}^{2}+\theta^{2} C_{x}^{2}-2 \theta C_{y x}\right)
\end{aligned}
$$

The optimum value of $\theta$ obtained by,

$\frac{\partial}{\partial \theta} \operatorname{MSE}\left(t_{p}\right)=0$, which gives, $\theta=\frac{C_{y x}}{C_{x}^{2}}$ and the minimum MSE for this optimum value of $\theta$ is given by,

$\operatorname{MSE}\left(t_{p}\right)=\lambda \bar{Y}^{2}\left[C_{y}^{2}-\frac{C_{y x}^{2}}{C_{x}^{2}}\right]$

\section{Efficiency Comparison}

Under this section, the proposed class of estimators is compared with the existing ratio-typeestimators of population-mean of study-variable and the conditions under which it performs better than existing estimators are given in the following Table 3 . The condition for the proposed class to be more efficient than the existing estimators is given by,

\begin{tabular}{|c|c|}
\hline Efficiency condition & Estimators \\
\hline$C_{y x}^{2}>0$ & Mean per unit estimator \\
\hline$\left[1-\rho_{y x}^{2}\right]-\left[C_{y}^{2}-\frac{C_{y x}^{2}}{C_{x}^{2}}\right]>0$ & $\begin{array}{l}\text { Watson (1937), Srivastava (1967), Reddy (1974), Nangsue (2009), Kadilar (2016), } \\
\text { Soponviwatkul and Lawson (2017), Ijaz and Ali (2018) estimators }\end{array}$ \\
\hline$\left[C_{x}^{2}-2 C_{y x}\right]+\frac{C_{y x}^{2}}{C_{x}^{2}}>0$ & Cochran (1940) estimator \\
\hline$\left[\frac{C_{x}^{2}}{4}-C_{y x}\right]+\frac{C_{y x}^{2}}{C_{x}^{2}}>0$ & Bahl and Tuteja (1991) estimator \\
\hline$\left[4 C_{x}^{2}-4 C_{y x}\right]+\frac{C_{y x}^{2}}{C_{x}^{2}}>0$ & Kadilar and Cingi (2003) estimator \\
\hline$\left[\theta_{i}^{2} C_{x}^{2}-2 \theta_{i} C_{y x}\right]+\frac{C_{y x}^{2}}{C_{x}^{2}}>0$ & $\begin{array}{l}\text { Sisodia and Dwivedi (1981), Upadhyaya and Singh (1999), Singh and Tailor (2003), } \\
\text { Singh et al. (2004), Al-Omari et al. (2009), Yan and Tian (2010), Subramani and } \\
\text { Kumarpandiyan (2012a, 2012b), Jeelani et al. (2013), Jerajuddin and Kishun (2016) } \\
\text { estimators }\end{array}$ \\
\hline
\end{tabular}

$\operatorname{MSE}\left(t_{i}\right)-\operatorname{MSE}\left(t_{p}\right)>0, i=0,1, \ldots, 30$

Table 3. Conditions under which proposed estimators are better than existing ones. 
International Journal of Mathematical, Engineering and Management Sciences

Vol. 4, No. 5, 1228-1238, 2019

https://dx.doi.org/10.33889/IJMEMS.2019.4.5-097

\section{Numerical Study}

For the verification of the conditions under which the proposed estimators are better than the existing estimators of population mean, we have used the primary data of production of peppermint oil, obtained from the crop from Banikodar Block at Barabanki District of Uttar Pradesh State in India. The parameters of the population under consideration are given in Table 4. The dependent variable and the auxiliary variables are as follows:

$Y$ : The production (Yield) of peppermint oil in kilogram $X$ : The area of the field in Bigha (2529.3 Square Meter)

Table 4. Parameters of the population

$N=150, \quad n=40, \quad \bar{X}=4.204667, \quad \bar{Y}=33.462, \quad S_{x}=3.080385, \quad S_{y}=25.50316$, $C_{x}=0.732611, C_{y}=0.762153, M_{x}=3, M_{y}=25, \rho_{y x}=0.911241, \beta_{1}(x)=2.801407$, $\beta_{2}(x)=16.44023, \quad \lambda=0.018333, \quad Q_{1}(x)=2, \quad Q_{3}(x)=5, \quad Q D=1.5, \quad Q_{a}(x)=3.5$, $Q_{r}(x)=3, T M=3.25$

The following Table 5 represents the variance or mean squared error of the existing and the proposed estimators along with the efficiency of the proposed class of estimators over other estimators. For calculating percentage relative efficiency of the proposed class over competing estimators, we have considered the least mean squared error of the proposed class.

Table 5. MSE of various estimators and PRE of proposed class over competing estimators

\begin{tabular}{|c|c|c|c|c|c|c|c|c|}
\hline Estimator & MSE & PRE & Estimator & MSE & PRE & Estimator & MSE & PRE \\
\hline$t_{0}$ & 11.92 & 596.04 & $t_{14}$ & 2.042 & 102.06 & $t_{28}$ & 2.023 & 101.11 \\
\hline$t_{1}$ & 2.023 & 101.11 & $t_{15}$ & 5.124 & 256.15 & $t_{29}$ & 2.023 & 101.11 \\
\hline$t_{2}$ & 2.053 & 102.60 & $t_{16}$ & 4.006 & 200.25 & $t_{30}$ & 2.023 & 101.11 \\
\hline$t_{2}$ & 4.234 & 211.64 & $t_{17}$ & 3.486 & 174.24 & $t_{p 1}$ & 2.016 & 100.80 \\
\hline$t_{4}$ & 14.22 & 710.63 & $t_{18}$ & 4.169 & 208.40 & $t_{p 2}$ & 2.014 & 100.67 \\
\hline$t_{5}$ & 2.023 & 101.11 & $t_{19}$ & 2.064 & 103.16 & $t_{p 3}$ & 2.011 & 100.54 \\
\hline$t_{6}$ & 2.023 & 101.11 & $t_{20}$ & 10.04 & 501.71 & $t_{p 4}$ & 2.009 & 100.42 \\
\hline$t_{7}$ & 2.023 & 101.11 & $t_{21}$ & 2.828 & 141.36 & $t_{p 5}$ & 2.007 & 100.31 \\
\hline$t_{8}$ & 2.023 & 101.11 & $t_{22}$ & 4.681 & 233.99 & $t_{p 6}$ & 2.015 & 100.72 \\
\hline$t_{9}$ & 2.125 & 106.23 & $t_{23}$ & 3.486 & 174.24 & $t_{p 7}$ & 2.011 & 100.53 \\
\hline$t_{10}$ & 8.127 & 406.22 & $t_{24}$ & 2.513 & 125.62 & $t_{p 8}$ & 2.002 & 100.08 \\
\hline$t_{11}$ & 3.356 & 167.75 & $t_{25}$ & 3.806 & 190.23 & $t_{p 9}$ & 2.004 & 100.19 \\
\hline$t_{12}$ & 2.198 & 109.87 & $t_{26}$ & 2.023 & 101.11 & $t_{p(\mathrm{~min})}$ & 2.001 & 100.00 \\
\hline$t_{13}$ & 8.902 & 444.98 & $t_{27}$ & 2.023 & 101.11 & & & \\
\hline
\end{tabular}


International Journal of Mathematical, Engineering and Management Sciences

Vol. 4, No. 5, 1228-1238, 2019

https://dx.doi.org/10.33889/IJMEMS.2019.4.5-097

Following Figure 1 and 2 show the MSE of various estimators along with the members of proposed class and the Percentage Relative Efficiency (PRE) of the proposed class of estimators over the competing estimators including its mentioned members as well. For PRE, we have used the least mean squared of the proposed class of estimators of population mean.

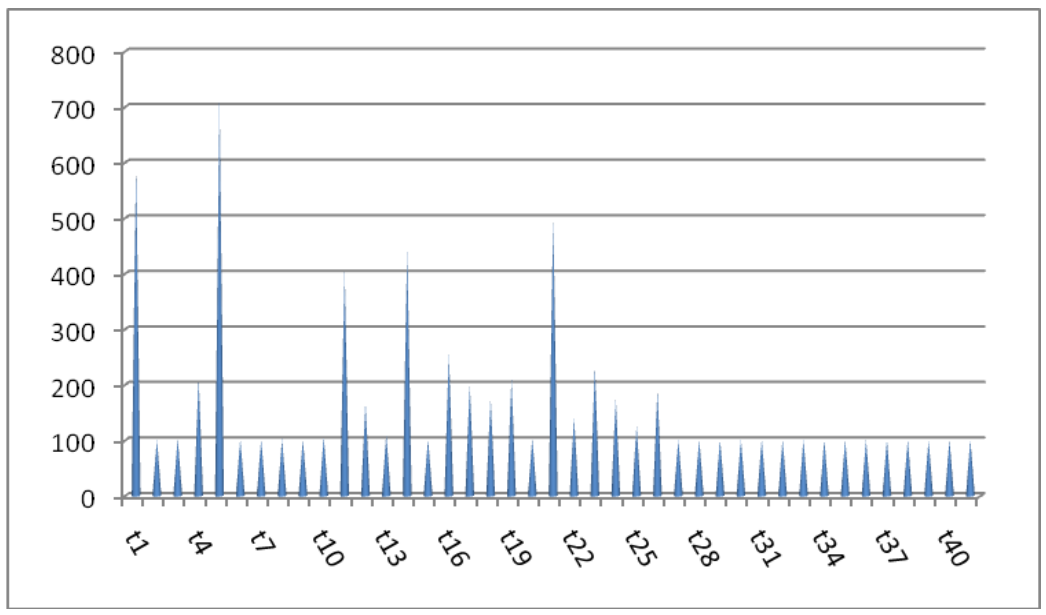

Figure 1. MSE of various estimators

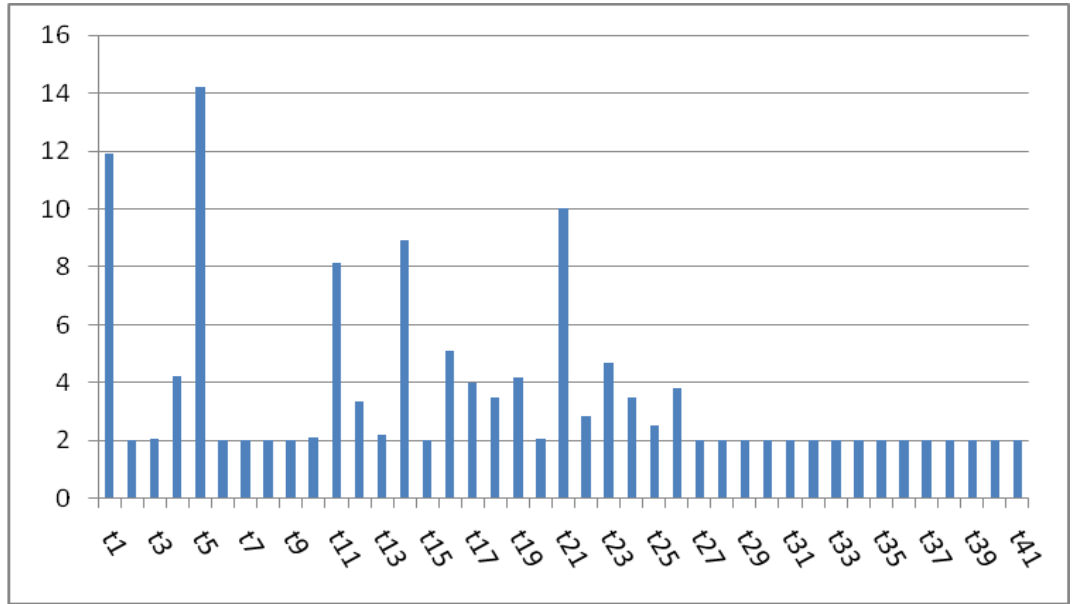

Figure 2. PRE of proposed over other estimators

\section{Results and Discussions}

From Table 5, it is evident that the members of the suggested class are having lesser MSE in comparison to all mentioned estimators of population-mean for the given population. The results are also presented in two figures namely Figure 1 and Figure 2, which respectively represent the MSE of various estimators along with the members of the proposed class and the PRE of the 
International Journal of Mathematical, Engineering and Management Sciences

Vol. 4, No. 5, 1228-1238, 2019

https://dx.doi.org/10.33889/IJMEMS.2019.4.5-097

proposed class over other competing estimators of population-mean under consideration. The variance of the sample mean is 11.92 whereas the MSE of Kadilar and Cingi (2003) estimator is 14.22. The MSE of all competing estimators are lying between 8.13 to 2.02, whereas proposed class has their MSE in between 2.02 to 2.002. The least value of the MSE of the suggested class is 2.0006, which is least among the class of all mentioned competing estimators.

\section{Conclusion}

In the present study, we have been able to suggest a class of estimators for estimating the average yield of the peppermint crop using information on the area of the field as the auxiliary-variable. We study the bias and MSE of the proposed class up to single order of approximation. The suggested class has been compared with the competing estimators of population-mean and the conditions for the suggested class to be better than the competing ones have been referred. A numerical study is also carried out using primary data to verify the theoretical results. It is evident from Table 5 that the proposed class has the least MSE among the competing estimators of population-mean, thereby fulfilling the purpose of the study. Thus, the suggested class may be applied for enhanced estimation of population-mean utilizing auxiliary-information under simple random sampling scheme.

\section{Conflict of Interests}

It is declared by the authors that there is no conflict of interests regarding the publication of this paper.

\section{Acknowledgement}

The authors are very much thankful to referees for critically reviewing the draft which improved the present version. The first author Dr. S. K. Yadav (PI) is thankful to Council of Science and Technology, Uttar Pradesh, Lucknow for the financial assistance in carrying out this research under the Project No. CST/4052.

\section{References}

Abid, M., Abbas, N. Sherwani, R.A.K., \& Nazir, H. Z. (2016). Improved ratio estimators for the population mean using non-conventional measure of dispersion. Pakistan Journal of Statistics and Operations Research, 12(2), 353-367.

Al-Omari, A.I., Jemain, A.A., \& Ibrahim, K. (2009). New ratio estimators of the mean using simple random sampling and ranked set sampling methods. Investigación Operacional, 30(2), 97-108.

Bahl, S., \& Tuteja, R.K. (1991). Ratio and product type exponential estimators. Journal of Information and Optimization Sciences, 12(1), 159-164.

Cekim, H.O., \& Cingi, H. (2017). Some estimator types for population mean using linear transformation with the help of the minimum and maximum values of the auxiliary variable. Hacettepe Journal of Mathemailcs and Statistics, 46(4), 685-694.

Cekim, H.O., \& Kadilar, C. (2018). Generalized family of estimators via two auxiliary variables for population variance. Journal of Reliability and Statistical Studies, 11(1), 67-81.

Cochran, W.G. (1940). The estimation of the yields of cereal experiments by sampling for the ratio of grain to total produce. The Journal of Agricultural Science, 30(2), 262-275. 
International Journal of Mathematical, Engineering and Management Sciences

Vol. 4, No. 5, 1228-1238, 2019

https://dx.doi.org/10.33889/IJMEMS.2019.4.5-097

Gupta, R.K., \& Yadav, S.K. (2017). New efficient estimators of population mean using non-traditional measures of dispersion. Open Journal of Statistics, 7(3), 394-404.

Gupta, R.K., \& Yadav, S.K. (2018). Improved estimation of population mean using information on size of the sample. American Journal of Mathematics and Statistics, 8(2), 27-35.

Ijaz, M., \& Ali, H. (2018). Some improved ratio estimators for estimating mean of finite population. Research \& Reviews: Journal of Statistics and Mathematical Sciences, 4(2), 18-23.

Jeelani, M.I., Maqbool, S., \& Mir, S.A. (2013). Modified ratio estimators of population mean using linear combination of co-efficient of skewness and quartile deviation. International Journal of Modern Mathematical Sciences, 6(3), 174-183.

Jerajuddin, M., \& Kishun, J. (2016). Modified ratio estimators for population mean using size of the sample, selected from population. International Journal of Scientific Research in Science, Engineering and Technology, 2(2), 10-16.

Kadilar, C., \& Cingi, H. (2003). A study on the chain ratio-type estimator. Hacettepe Journal of Mathematics and Statistics, 32, 105-108.

Kadilar, G.O. (2016). A new exponential type estimator for the population mean in simple random sampling. Journal of Modern Applied Statistical Methods, 15(2), 207-214.

Murthy, M.N. (1964). Product method of estimation. Sankhyā: The Indian Journal of Statistics, Series A, 69-74.

Nangsue, N. (2009). Adjusted ratio and regression type estimators for estimation of population mean when some observations are missing. International Journal of Mathematical and Computational Sciences, 3(5), 334-337.

Reddy, V.N. (1974). On a transformed ratio method of estimation. Sankhya-C, 36, 59-70

Robson, D.S. (1957). Applications of multivariate polykays to the theory of unbiased ratio-type estimation. Journal of the American Statistical Association, 52(280), 511-522.

Singh, H.P., \& Tailor, R. (2003). Use of known correlation coefficient in estimating the finite population mean. Statistics in Transition, 6(4), 555-560.

Singh, H.P., Tailor, R., Tailor, R., \& Kakran, M.S. (2004). An improved estimator of population mean using power transformation. Journal of the Indian Society of Agricultural Statistics, 58(2), 223-230.

Sisodia, B.V.S., \& Dwivedi, V.K. (1981). A modified ratio estimator using coefficient of variation of auxiliary variable. Indian Society of Agricultural Statistics, 33(2), 13-18.

Solanki, R.S., Singh, H.P., \& Rathour, A. (2012). An alternative estimator for estimating the finite population mean using auxiliary information in sample surveys. ISRN Probability and Statistics, 2012. Article ID 657682, 14 pages, doi:10.5402/2012/657682.

Soponviwatkul, K., \& Lawson, N. (2017). New ratio estimators for estimating population mean in simple random sampling using a coefficient of variation, correlation coefficient and a regression coefficient, Gazi University Journal of Science, 30(4), 610-621.

Srija \& Subramani, J. (2018). Modified ratio cum product estimators for finite population mean with known median and mean. SSRG International Journal of Economics Management Studies, Special Issue ICRTECITA April 2018, 1-9.

Srivastava, S.K. (1967). An estimator using auxiliary information in sample serveys, Calcutta Statistical Association Bulletin, 16(2-3), 121-132. 
International Journal of Mathematical, Engineering and Management Sciences

Vol. 4, No. 5, 1228-1238, 2019

https://dx.doi.org/10.33889/IJMEMS.2019.4.5-097

Subramani, J. \& Kumarapandiyan, G. (2012a). Estimation of population mean using co-efficient of variation and median of an auxiliary variable. International Journal of Probability and Statistics 1(4), $111-118$.

Subramani, J. (2016). A new median based ratio estimator for estimation of the finite population mean. Statistics in Transition. New Series, 17(4), 591-604.

Subramani, J., \& Kumarapandiyan, G. (2012b). Estimation of population mean using known median and co-efficient of skewness. American Journal of Mathematics and Statistics, 2(5), 101-107.

Subramani, J., \& Master Ajith, S. (2017). Improved ratio cum product estimators for finite population mean with known quartiles and their functions. SM Journal of Biometrics \& Biostatistics, 2(1), 1008.

Upadhyaya, L.N., \& Singh, H.P. (1999). Use of transformed auxiliary variable in estimating the finite population mean. Biometrical Journal: Journal of Mathematical Methods in Biosciences, 41(5), 627636.

Watson, D.J. (1937). The estimation of leaf area in field crops. The Journal of Agricultural Science, 27(3), 474-483.

Yadav, S.K., \& Kadilar, C. (2013). Improved class of ratio and product estimators. Applied Mathematics and Computation, 219(22), 10726-10731.

Yadav, S.K., \& Mishra, S.S. (2015). Developing improved predictive estimator for finite population mean using auxiliary information. Statistika-Statistics and Economy Journal, 95(1), 76-85.

Yadav, S.K., Gupta, S., Mishra, S.S., \& Shukla, A.K. (2016). Modified ratio and product estimators for estimating population mean in two-phase sampling. American Journal of Operational Research, 6(3), 61-68.

Yadav, S.K., Sharma, D.K., Mishra, S.S., \& Shukla, A.K. (2018). Use of auxiliary variables in searching efficient estimator of population mean. International Journal of Multivariate Data Analysis, 1(3), 230244.

Yan, Z., \& Tian, B. (2010). Ratio method to the mean estimation using coefficient of skewness of auxiliary variable. In: Zhu R., Zhang Y., Liu B., Liu C. (eds) Information Computing and Applications. ICICA 2010. Communications in Computer and Information Science, vol 106. Springer, Berlin, Heidelberg. 